Proceedings of the 2011 Winter Simulation Conference

S. Jain, R.R. Creasey, J. Himmelspach, K.P. White, and M. Fu, eds.

\title{
SPREADSHEET BASED EXPERIENTIAL LEARNING ENVIRONMENT FOR PROJECT MANAGEMENT
}

\author{
Wee-Leong Lee \\ Singapore Management University \\ School of Information Systems \\ 80 Stamford Road \\ SINGAPORE 178902
}

\begin{abstract}
Research has demonstrated that people learn best when they are actively involved in the learning process. Games and simulations are especially effective as discovery learning approaches since they pull learners into the learning experience in interesting, fun and challenging ways. This article seeks to demonstrate the effective use of simulation and gaming technique in providing an engaging and high-energy approach to teaching the concepts and best practices of project management that will have practical and lasting value. The project management game described here provides a means of immersing people in situations that mimic the complexities of the real world, challenging them to take risks and make mistakes without real consequences.
\end{abstract}

\section{INTRODUCTION}

A gap exists between the skills taught in a project management course in university and the skills that are actually desired of a project manager. This problem seems to stem from the way project management is typically introduced to students. Theory and concept are presented in lectures with examples drawn from case studies. There is little opportunity for students to apply the concepts in a classroom setting. Although lectures and case studies are essential in knowledge transfer, they lack a practical, in-depth treatment of the overall process of project management. Lectures usually limit the amount of interaction - teacher to students - allowing only passive learning. The size and scope of cases are often too constrained to exhibit many of the fundamental characteristics of real-world project management issues.

To address this problem, I experimented with computer-based simulation games to teach project management, with favorable results. I designed a spreadsheet based gaming environment for small group learning that includes activities such as project planning, monitoring, and execution. In the game, students are to manage a "virtual" IT project and encounter typical project management issues such as team dynamics, time sensitive decision-making, personality conflicts, team motivations, different expectations of stakeholders, meeting budgets, quality issues, meeting deadlines and responding to random unexpected events. The rapid and flexible nature of simulation allows experiences to be repeated, different situations to be introduced and practiced, and promotes a general freedom of experimentation and "play" in the training exercise. By analyzing past situations and evaluating a different path that the project could have taken if specific decisions were made at particular junctures of the project, students can develop their management and decision making skills. This experiential learning platform for project management creates an environment where students can act as managers without the costs and risks associated with an unsuccessful project. 


\section{SIMULATION AND GAMING}

In most real-world situations where there is no exact analytical solution, computer simulation becomes particularly useful to analyze systems that exhibit randomness in their behavior. For analyzing such complex systems with uncertainties, simulation is often the only scientific methodology available and feasible for practitioners. Simulation enables experimentation with physical systems that would otherwise be impractical, risky, time consuming, or too expensive to conduct. It allows multiple replications of a scenario to gain statistically reliable measures and variability with precise control of their influencing factors. As such, decision makers can rapidly evaluate different options to optimize the performance for a given objective function.

Despite such rich body of knowledge in simulation, which has expanded into areas such as visualization, animation, and virtual reality applications for project management, the beneficial application of simulation in practice has been marginal. Lucko, Benjamin, and Madden (2008) described both historical and practical reasons for this situation and presented an ontology-based approach that can harness existing information in construction project management.

Existing discrete event simulation tools (e.g. Arena, Witness, ProModel, Extend, etc.) are designed to support generic requirements for process modeling and analysis. Many of these commercial packages were developed to simulate manufacturing and logistics processes, which are characterized by known flows of parts-in-progress between service stations in a controlled factory environment. The capabilities offered by these tools are often generic and are not easily customized for application domains that are outside their intended scope.

The problems, uncertainties and dynamics associated with project management make it an ideal topic for employing simulation and gaming when teaching it. Allowing a computer to control the pace of decision making provides the realism and flexibility necessary to stimulate and enhance learning (Hall 1994). The PROTEST - Project Management Simulation (Hall 1994) was developed for the Winning and Managing Major Projects (WAMMP) course run by the GEC Management College, Dunchurch, England. The PROTEST simulation is divided into several sessions where access to the software is only provided to do specific tasks. Between these sessions, access to the computer is denied and participants are required to reflect and prepare for the next session (Hall 1994). Computer pacing is particularly appropriate for the simulation of project management activities where time constraints is one major consideration. The ability to think under pressure and manage proactively rather than reactively is particularly important to a project manager. Although PROTEST employed computer pacing, decision activities occur at preset intervals rather than by event-driven or random manner and hence it lacks realism.

Wang and Tseng (2010) examined what factors would determine the learner acceptance of a gamebased project management learning platform. They found that self-efficacy is significant in using online games. The higher a persons' self-efficacy, the less anxiety that person has in using a project management platform. Compeau and Higgins (1995) found that high self-efficacy can both relieve anxiety and increase positive influence in using a computer. Agarwal, Sambamurthy, and Stair (2000) on the other hand suggested that self-efficacy is more related to perceived ease of use than to perceived usefulness. Interpersonal interaction among students creates a community in which educational value can be created by improving learning interest and efficiency. When students use the game-based learning platform intensely, the interaction with other students will cause more to join in (Wang and Tseng 2010).

Interactive simulation gaming occupies an important place in system dynamics modeling methodology. Sterman and Meadows (1985) presented STRATEGEM-2, a macroeconomic management game. Barlas and Bayraktutar (1992) developed a simulation game for software project management (SOFTSIM). Graham, et al. (1992) summarized several case-based games. Mohapatra and Saha (1996) described a simulation game for new product growth while Anderson et al. (1990) discussed the key issues in designing games based on system dynamics models. Mishra et al. (2009) developed a simulation game of a project management situation for both an individual and team model with non-competitive and competitive model. The game simulates a project that needs to be completed within a specific time limit and under a stated budget. The simulated project is broken down into four periods in which the players received feed- 
back and can make necessary changes in order to complete the project on time and under budget in only the last three time periods. Shtub (2010) presented a project management tool - The Project Team Builder - for teaching practitioners and students project management that can easily integrate into traditional teaching based on any course or textbook. The Project Team Builder software tool combines an interactive, dynamic case study and a simple yet effective Project Management System.

Some of the benefits of games and simulations listed by Grieshop (1987) include providing opportunities to examine critically the assumptions and implications that underlie various decisions, creating an environment for experiential learning and discovery and encouraging communication, group problem solving and collective decision making. These benefits are excellent processes in learning project management. A well designed simulator supports a process of action-based learning. Instead of talking about different ways of doing things, simulators offer an opportunity to try different ways of doing things without risking the consequences of doing so in the real world (Shtub 2010).

To use simulation and gaming as an effective teaching aid, the tool must be simple and fun to use so as to draw students into a process of self discovery and learning through experimentation. The remainder of this article further details the simulation game that was designed to achieve that.

\section{PRINCIPLE OF THE SIMULATION GAME}

The pervasiveness of spreadsheets has resulted in its increased application as a simulation tool for business analysis (Leong and Lee 2008, 2010). Random value generation in support of such evaluations using spreadsheets is simple and yet powerful. Microsoft Excel spreadsheet with its versatile layout could serve as a database or graphical user interface (GUI); coupled with its excellent graphing utility, makes it an excellent platform for rapid prototyping small applications. Complex algorithms and customized functions can be included using the VBA programming language embedded in Excel albeit there may be latency issues as the application gets larger. To avoid system incompatibility issues, only standard Excel functions were used in the simulation game.

The project management game was designed as a teaching tool to facilitate the training of project management in a classroom setting which allows participants to encounter firsthand what real project management entails. In the game, participants learn to respond to unforeseen events and make sound decisions to resolve problems while minimizing any compromise to project schedule, cost, quality or scope. Essentially, they do what it takes as a project manager to keep the project on track and on target. The objective of the game is for students to appreciate and experience the complexity of project management in an intense and yet exciting way. Through playing this game, students will understand that project management is not just about preparing and maintaining a set of charts and templates or about being an effective communicator, it is a combination of both and much more. Students will learn the intricacies of managing project tradeoffs between budget, schedule, quality and motivation.

The game can be played individually or in a group, although the latter is preferred to encourage exchange of ideas and open communications to achieve the effects of cross learning. In the game, participants are tasked to plan and manage a "virtual" IT project. The project consists of a set of interdependent activities and participants are to manage the planning and execution of these activities while satisfying the performance criteria. There are two phases in the game that run consecutively. The first phase requires participants to create a project plan that involves building a Gantt Chart, Network Diagram and Training Plan (optional). The second phase involves executing the project according to the project plan developed in phase one. Events and situations will emerge during project execution and participants are to exercise good judgment in making the right decisions to steer the project towards completion.

The main user interface (UI) shown in Figure 1 consists of performance indicators, charts, navigation buttons, decision scores and a simulation clock. The simulation clock only activates at the start of project execution. One day in the simulation is equivalent to three minutes in real time (can be configured). The decision score shows the cumulative scores for correct decisions made. The customer satisfaction index indicates the customer satisfaction level which is a weighted sum of the four performance indices (budget, quality, motivation and schedule), scope management (percentage of scope reduction) and decision score. 


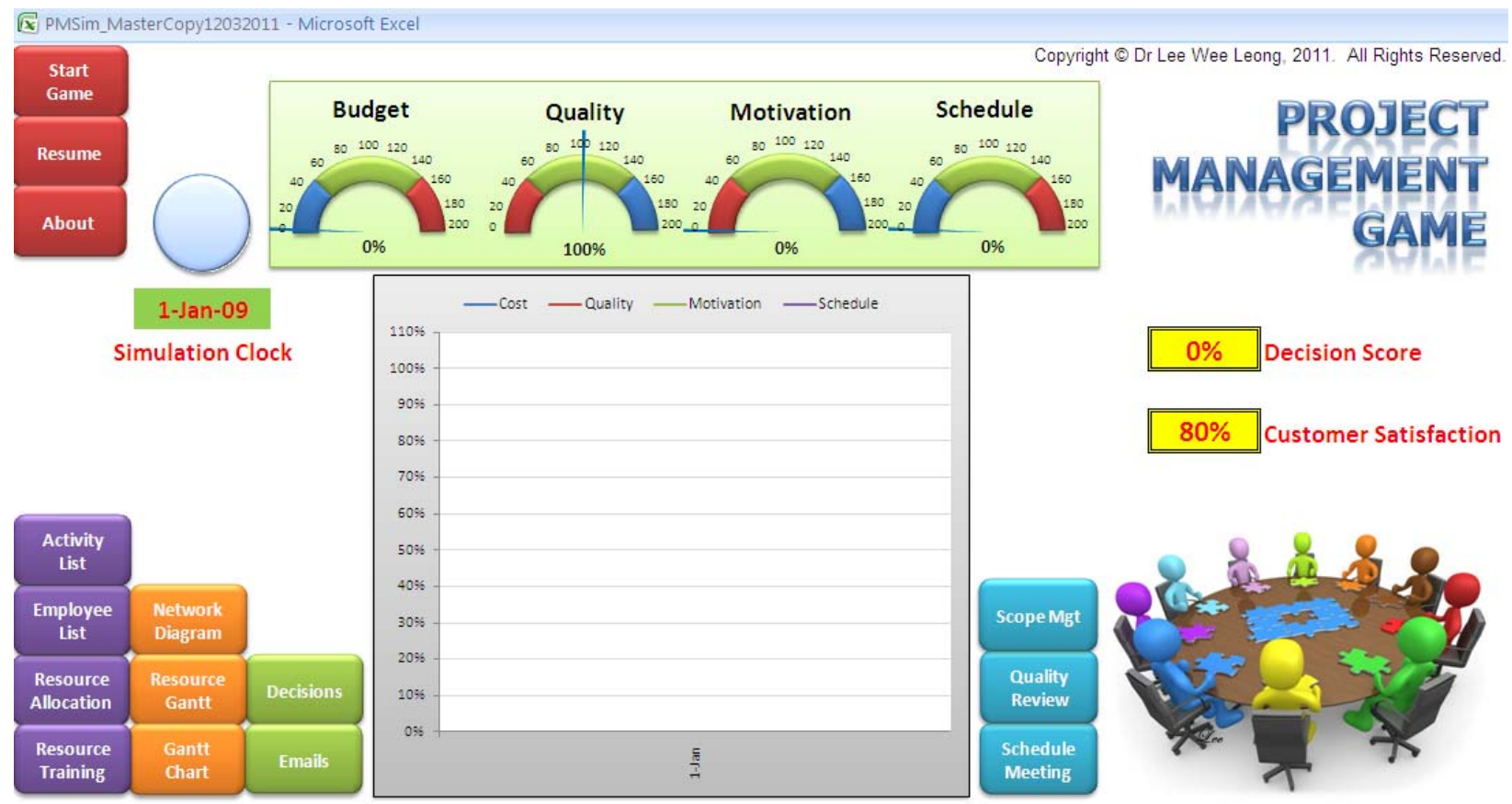

Figure 1: Project management game interface

The chart in the middle of the game UI shows the historical performance of the four performance indices over time. Clicking on the purple and orange buttons to the left of the main UI will show screens with the details of activities, employees, resource allocation, resource training, network diagram, resource Gantt chart and schedule Gantt chart. As for the two green buttons, one is for making decisions and the other for reading emails when prompted. Clicking on the three light blue buttons to the right of the chart will show screens for making adjustments to project scope, scheduling quality review and scheduling of meetings or organizing activities. The three red buttons are used for starting and resuming the project execution and instructions for the game.

The game is ideally played by four people, with each person accounting for one of the four performance indices. This will compel players to collaboratively negotiate tradeoffs between performance indices when making decisions. Depending on the circumstances, the outcome of a decision may vary according to the progress of the project at that moment. This is where participants are exposed to the multivariant decision making process typical in project management which if managed well could minimize potential risk of project failure.

Decisions made will have direct or indirect consequences (whether positive or negative) on one or more of the four performance indices. The interactions between these performance indices are illustrated in Figure 2 (note: players do not have access to this influence diagram before playing the game).

\subsection{Project Planning Phase}

The main task in the project planning phase is to build the Gantt chart to form a project baseline by assigning suitable resources to project activities. To do that, participants need to understand their team members' skill sets and match it to the activities. Achieving an ideal project plan can be challenging as team members' availability is another key consideration beside matching skill sets. An ideal resource with matching skill sets to an activity may not be available during the required period. Other constraints include group dynamics and team members motivation issues. Figures 3 and 4 show the project activities and team member details respectively. 


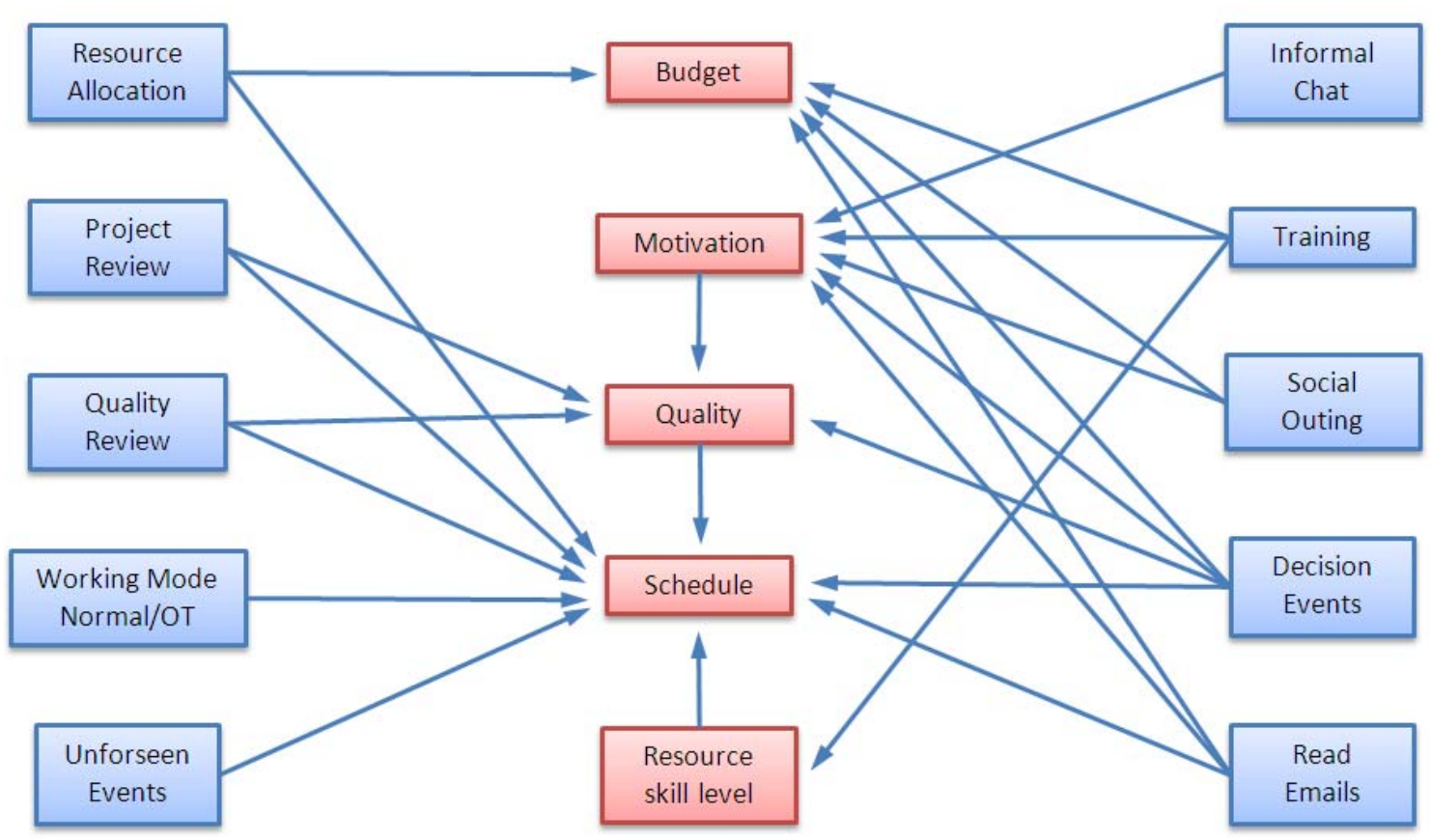

Figure 2: Interactions between parameters

\section{Activity Information}

\begin{tabular}{|c|c|c|c|c|c|c|c|c|}
\hline \multirow[b]{2}{*}{ No } & \multirow[b]{2}{*}{ Activities } & \multicolumn{5}{|c|}{ Required Skills } & \multirow[b]{2}{*}{$\begin{array}{c}\text { Recommended } \\
\text { Resource for } \\
\text { Activity }\end{array}$} & \multirow[b]{2}{*}{ Mandays } \\
\hline & & Web Design & Database & Programming & Business & $\begin{array}{r}\text { Sales and } \\
\text { Marketing }\end{array}$ & & \\
\hline 1 & Specification & 2 & 2 & 2 & 5 & 3 & 3 & 15 \\
\hline 2 & ePayment Concept & 4 & 3 & 2 & 4 & 3 & 2 & 14 \\
\hline 3 & Marketing Concept & 3 & 1 & 1 & 3 & 5 & 2 & 12 \\
\hline 4 & Pricing Concept & 2 & 3 & 3 & 3 & 4 & 2 & 10 \\
\hline 5 & User Interface & 5 & 2 & 1 & 2 & 1 & 2 & 10 \\
\hline 6 & Database Design & 2 & 6 & 3 & 1 & 0 & 2 & 10 \\
\hline 7 & Software Prototype & 4 & 3 & 4 & 1 & 2 & 3 & 21 \\
\hline 8 & Data Import & 1 & 4 & 2 & 2 & 0 & 2 & 8 \\
\hline 9 & Implementation & 3 & 3 & 5 & 1 & 0 & 3 & 42 \\
\hline 10 & Functional Tests & 2 & 3 & 2 & 3 & 0 & 2 & 6 \\
\hline 11 & Integration & 3 & 2 & 5 & 1 & 1 & 3 & 21 \\
\hline 12 & Application Test & 2 & 2 & 3 & 2 & 0 & 2 & 6 \\
\hline 13 & Deployment & 2 & 3 & 4 & 3 & 0 & 2 & 10 \\
\hline 14 & User Manual & 2 & 2 & 2 & 3 & 1 & 2 & 10 \\
\hline 15 & UAT & 1 & 2 & 3 & 3 & 3 & 2 & 10 \\
\hline 16 & Debugging & 3 & 3 & 6 & 1 & 0 & 2 & 40 \\
\hline 17 & Documentation & 1 & 1 & 2 & 1 & 1 & 2 & 6 \\
\hline
\end{tabular}

Figure 3: Project activity details 
Lee

\begin{tabular}{|c|c|c|c|c|c|c|c|c|}
\hline \multirow[t]{2}{*}{ Home } & $\begin{array}{l}\text { Resource } \\
\text { Allocation }\end{array}$ & \multicolumn{5}{|c|}{ Employee Information } & & \\
\hline & & \multicolumn{5}{|c|}{ Employee Skills } & & \\
\hline No & $\begin{array}{l}\text { Employee } \\
\text { Name }\end{array}$ & Web Design & Database & Programming & Business & $\begin{array}{l}\text { Sales and } \\
\text { Marketing }\end{array}$ & Daily Rate & $\begin{array}{l}\text { Mode of } \\
\text { Working }\end{array}$ \\
\hline 1 & Alex & 4 & 1 & 3 & 2 & 0 & 100 & Normal \\
\hline 2 & Ben & 3 & 2 & 2 & 1 & 0 & 80 & Normal \\
\hline 3 & Bryan & 4 & 3 & 4 & 2 & 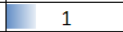 & 140 & Normal \\
\hline 4 & Jack & 3 & 3 & 5 & 1 & 0 & 120 & Normal \\
\hline 5 & Jane & 2 & 2 & 2 & 5 & 4 & 150 & Normal \\
\hline 6 & Jenny & 2 & 1 & 5 & 2 & 10 & 150 & Normal \\
\hline 7 & Jerry & \multirow{5}{*}{\multicolumn{7}{|c|}{$\begin{array}{l}\text { Personality } \\
\text { He is an idealist and is a rather creative person who spends most of his pastimes designing and } \\
\text { enhancing his own web sites. He is not a fast worker though and tends to make quite a fair } \\
\text { amount of mistakes. Personally, he is very sociable and loves to talk and at times, people may } \\
\text { find him rather annoying because he never stop talking. He enjoys working in a group and } \\
\text { dislike working overtime. }\end{array}$}} \\
\hline 8 & John & & & & & & & \\
\hline 9 & Lin & & & & & & & \\
\hline 10 & Lucy & & & & & & & \\
\hline 11 & $\mathrm{Mal}$ & & & & & & & \\
\hline 12 & Mike & \multicolumn{7}{|l|}{ Experience } \\
\hline 13 & Paul & \multirow{2}{*}{\multicolumn{7}{|c|}{$\begin{array}{l}\text { He has several years of experience in sales and picks up his computer skills out of interest in } \\
\text { Web designing. }\end{array}$}} \\
\hline 14 & Sue & & & & & & & \\
\hline 15 & Susan & \\
\hline 16 & Tom & \multicolumn{7}{|c|}{ Diploma in Mass Communications. } \\
\hline & & \multicolumn{7}{|c|}{$\begin{array}{l}\text { Years with Company } \\
\text { He has been with the company for three years. }\end{array}$} \\
\hline
\end{tabular}

Figure 4: Team member details

From past observations, participants often spend too much time trying to produce a perfect project plan without realizing that their plan will inevitably be disrupted once project execution starts. It is important to emphasize that all plans are subject to changes; anticipating and managing change is part and parcel of project management. Figures 5 and 6 show the Gantt Chart and Network Diagram which are the outcome of the planning phase.

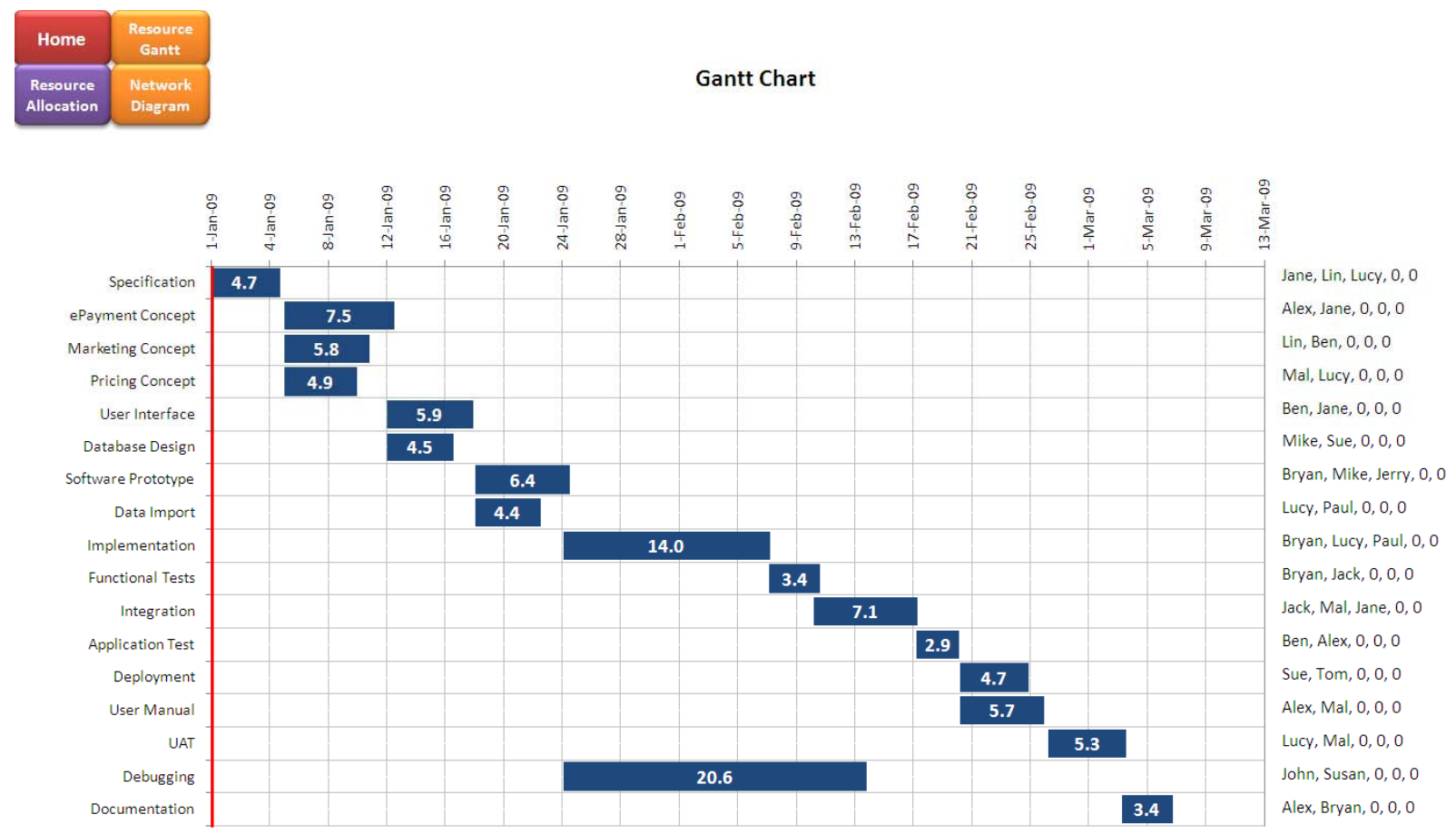

Figure 5: Gantt chart 


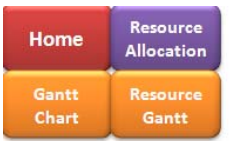

Activity Network Diagram (Critical Path)

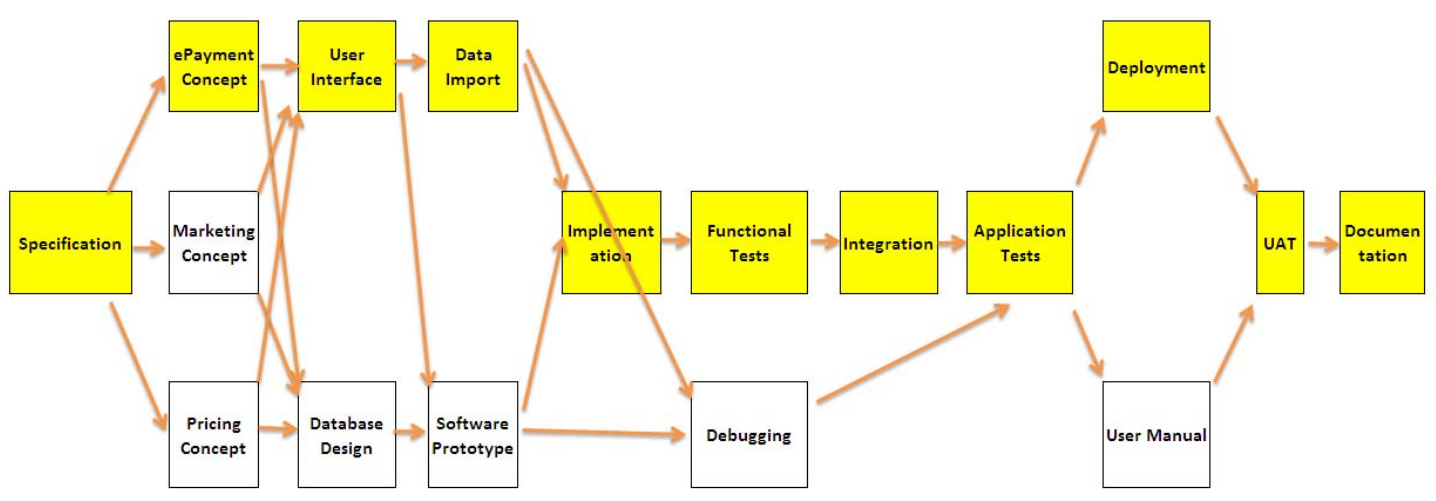

Figure 6: Network diagram

Throughout the game, team members can be sent for training to upgrade their skills. Project managers often give staff training a lower priority. When projects are behind schedule, which happens quite often, most manager will work their team member overtime to catch up. However, it is a good practice to have a training plan not only to ensure constant skill upgrading but also helps to boost morale within the team. In the game, team members who returned after a training session will have their overall skill set level improved by one.

\subsection{Project Execution and Control Phase}

Once project execution is initiated, the simulation clock will start and not stop until it reaches the end of period 1 (around 6 weeks). Any decisions or actions taken by participants are done with urgency in simulated real-time. The continuous real-time simulation feature, which is uncommon in most project management games reviewed, is intentionally incorporated into the game to induce urgency and stress on the participants in their decision making process. Throughout the project execution phase, participants need to regularly attend to decision events (Figure 7), read emails (Figure 8) and respond to unforeseen situations. There are about 40 decision events throughout the game that will emerge from time to time and demand immediate attention and resolution by the participants. These decision events require players to discuss and negotiate tradeoffs before arriving at a consensus decision that impact (either positively or negatively) one or more of the four performance indices. Email is the only means of communication between project stakeholders (sponsor, boss, vendors, team members, etc.) and the participants. Important messages from stakeholders and situation alerts are communicated via emails. Not reading emails could result in missing crucial information that could jeopardize the project.

Participants also need to plan for quality reviews (Figure 9), project reviews, organize social events and meet up with team members (Figure 10). Failure to perform these activities will have negative consequences on the performance indicators. The game engine will cause the performance indicators to decline gradually over time if the participants do not proactively perform these activities. For instance, without quality reviews, the quality of the project deliverables will deteriorate. These activities may consume a small amount of time and cost or affect motivation level depending on the nature of the activities; participants are to ascertain what and how much of these activities are appropriate. 


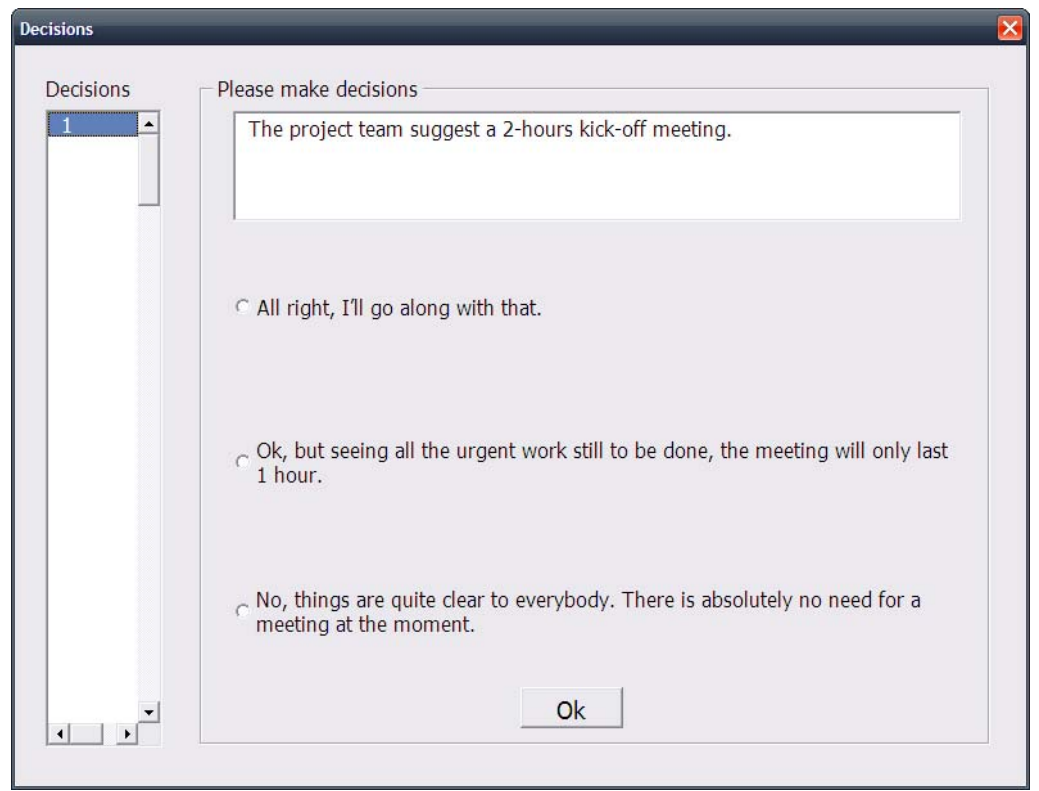

Figure 7: Decision event

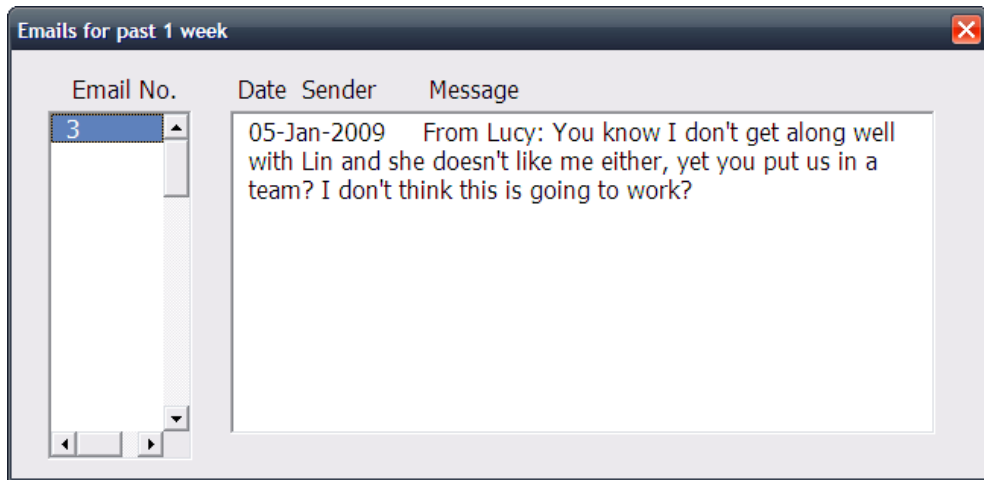

Figure 8: Email alert

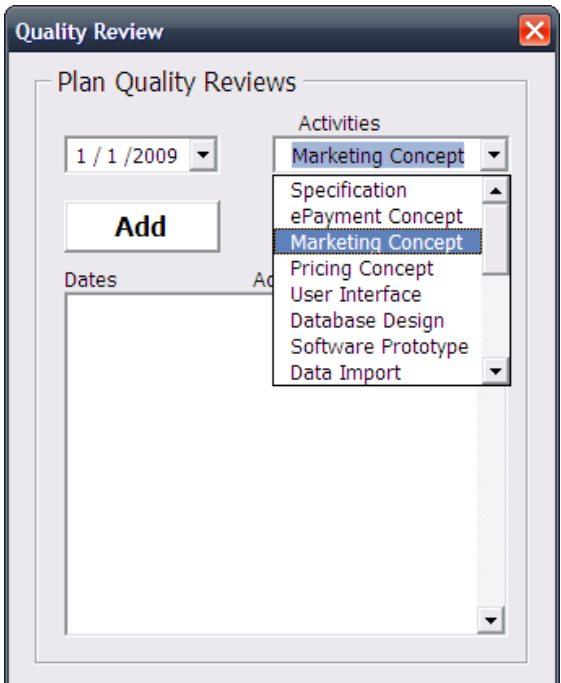

Figure 9: Quality review 


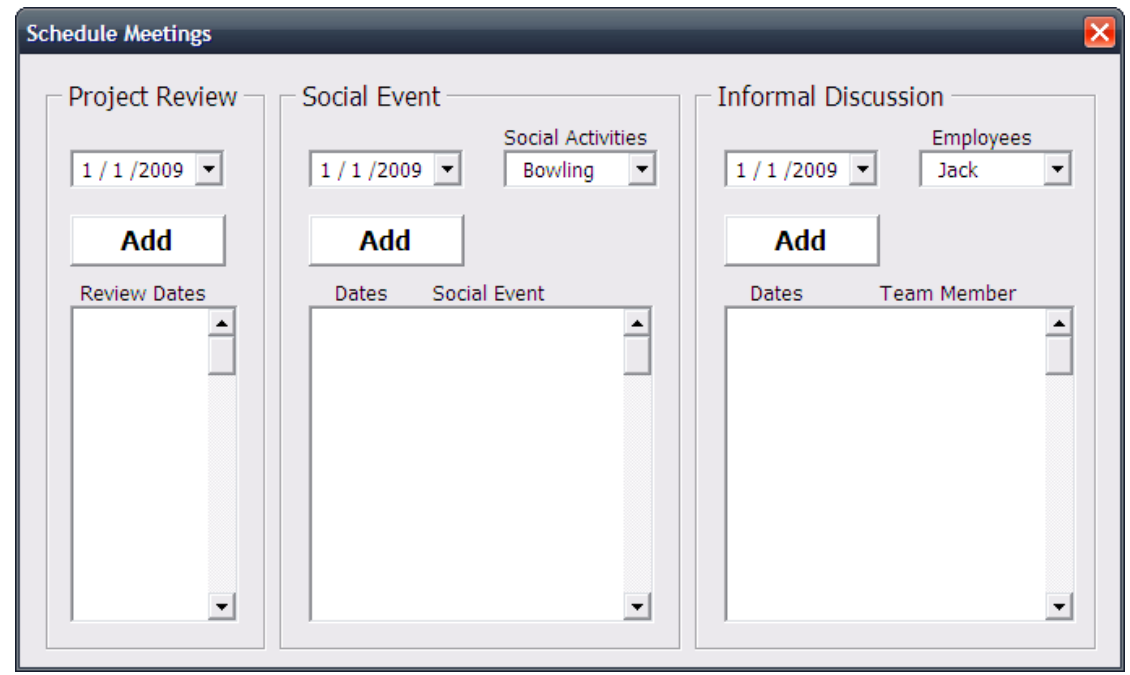

Figure 10: Schedule meeting

There are two periods in the project execution phase. Project execution will temporary halt at the end of the first period to allow players to review their performance and re-strategize (make necessary changes to the project plan) for the next period. At the end of period 1, most participating teams would run into problems with one or more performance indices falling below their expectations. This recess period gives players an opportunity to evaluate whether their actions and decisions taken were effective in steering the project towards success.

At the end of period 2, the game will terminate even if the project was not completed. Projects completed before the end of period 2 will be considered successful although the degree of success is measured by how well the players have achieved on the four performance indices, decision score and customer satisfaction index.

\section{CONCLUSION}

This game was originally designed for a Masters level IT project management course but had been played by both undergraduate and Master's students. The game is usually played in groups of three or four and up to eight groups per class. Typically, only two to three groups manage to complete the project "successfully" albeit with some budget overrun. The project success rate of the game reflects what happens in reality, with $20-30 \%$ of IT projects completed successfully.

The following are some feedback from students.

"The project management game is a well thought-out, well designed, with neatly packed simulation that has (mostly) all the tools and features integrated in, to provide participants a 'taste' of what real project management is like."

"This game gives project managers a simulation of how a project in the real world might start and end with proper planning. Therefore, this game provides project managers an avenue to improve their way of managing projects."

"Through the game, my team experienced not just budget constraints to meet project schedules, but also having to make sure that the people assigned to the tasks are comfortable with each other! The game does not just end at the project planning phase. Once the schedule starts; we are met with lots of decision making situations and unforeseen events that can change the course of the project. When things are not going smoothly as we thought, we have to reallocate our resources, organize meetings, quality checks, trainings, informal/personal chat, and even social outings to get things back on track."

"The game really made us realize how our perfect plan could be ruined as the time passed by. Problems and obstacles kept bombarding us; they accumulated if not taken care of. I guess that's how it is in 
the real life: people get sick, become unmotivated, and don't necessarily work well with others. Nonetheless, there are surely ways that we can do to mitigate those adverse impacts, such as by sending them to training, holding social events, or spending more time connecting with them. This game taught us how stressful project manager's life can be (juggling scope, quality, schedule, and budget on track) but at the same time, also how rewarding it is when you can successfully complete the project."

In conclusion, this article presents an overview of the project management simulation game developed using Microsoft Excel. The simulation game provides a simple and effective platform for students and practitioners to exercise the science and art of making tradeoffs between schedule, scope, cost, and quality while solving project management problems. Judging from students' feedback, the game has achieved its desired objectives of teaching the concepts and best practices in project management in a fun, interactive and practical manner.

\section{REFERENCES}

Agarwal, R., V. Sambamurthy, and R. Stair. 2000. "The Evolving Relationship between General and Specific Computer Self-Efficacy.” Information Systems Research 11:418-430.

Andersen, D. F., I. J. Chung, G. P. Richardson, and T. R. Stewart. 1990. "Issues in Designing Interactive Games Based on System Dynamics Models." In Proceedings of the International System Dynamics Conference, edited by D. F. Andersen, G. P. Richardson, and J. D. Sterman, 31-45.

Barlas, Y., and I. Bayraktutar. 1992. "An Interactive Simulation Game for Software Project Management." In Proceedings of the International System Dynamics Conference, 59-68. Utrecht, The Netherlands.

Compeau, D., and C. Higgins. 1995. "Computer Self-Efficacy: Development of a Measure and Initial Test." MIS Quarterly 19:189-211.

Graham, A. K., J. D. W. Morecroft, P. M. Senge, and J. D. Sterman. 1992. "Model-Supported Case Studies for Management Education." European Journal of Operational Research 59:151-166.

Grieshop, J. I. 1987. "Games: Powerful Tools for Learning.” Journal of Extension 25(1). Accessed July 23, 2011. http://www.joe.org/joe/1987spring/iw2.php.

Hall, J. J. S. B. 1994. “Computer Paced Project Management Simulation.” Development in Business Simulation and Experiential Exercises 21:174-175.

Leong, T. Y., and W. L. Lee. 2008. "Spreadsheet Data Resampling for Monte-Carlo Simulation." Spreadsheets in Education 3(1):70-78.

Leong, T. Y., and W. L. Lee. 2010. "Spreadsheet Modeling to Determine the Optimum Hotel Room Rate for a Short High-Demand Period." INFORMS Transactions in Education 11(1):35-42.

Lucko, G., P. C. Benjamin, and M. G. Madden. 2008. "Harnessing the power of simulation in the project management/decision support aspects of the construction industry." In Proceedings of the Winter Simulation Conference, edited by S. J. Mason, R. Hill, L. Moench, and O. Rose, 2479-2487. Piscataway, New Jersey: Institute of Electrical and Electronics Engineers, Inc.

Mishra, N., A. Malbotra, K. Sibal, G. Otioiu, K. H. Greess, K. Tuli, and R. Teach. 2009. "Project Competitor (C) A simulation Game for Project Management with 2 Models and 2 Modes." Developments Business Simulation and Experiential Learning 36:199-204.

Mohapatra, P. K. J., and B. K. Saha. 1996. "A System Dynamics-Based Game for New Product Growth.” Simulation and Gaming 27:238-260.

Shtub, A. 2010. "Project Management Simulation with PTB Project Team Builder." In Proceedings of the 2010 Winter Simulation Conference, edited by B. Johansson, S. Jain, J. Montoya-Torres, J. Hugan, and E. Yücesan, 242-253. Piscataway, New Jersey: Institute of Electrical and Electronics Engineers, Inc.

Sterman, J. D., and D. L. Meadows. 1985. "STRATEGEM-2: A Micro-Computer Simulation Game of the Kondratiev Cycle." Simulation and Games 16:174-202. 
Wang, T. L., and Y. S. Tseng. 2010. "Developing and Evaluating a Game-Based Project Management Learning Platform." In Proceedings of the IEEE EDUCON Conference -The Future of Global Learning Engineering Education, 1391-1394.

\section{AUTHOR BIOGRAPHIES}

WEE-LEONG LEE is an Assistant Professor of Information Systems (Practice) at the School of Information Systems, Singapore Management University. He obtained his BEng (Honours Class I) in Mechanical Engineering from the University of Leeds (UK), MEng from the Nanyang Technological University (Singapore) and $\mathrm{PhD}$ from the Imperial College London (UK). He formerly headed the R\&D department at Y3 Technologies (a supply chain solutions provider) and was responsible for developing and implementing supply chain solutions and providing consultancy in network design optimization, vehicle routing optimization and Business Process Re-engineering. Before joining Y3, he was a Research Fellow at the Singapore Institute of Manufacturing Technology (a national R\&D institute) and was engaged in applied research activities in the area of demand forecasting, vehicle routing optimization, loading optimization and RFID solutions. In his earlier career, he spent several years in the oil \& gas and aerospace industry as an engineer. His research interests are in supply chain optimization, project management and simulation modeling and he has published articles in academic journals, book chapters and presented papers at international conferences. His email address is wllee@smu.edu.sg. 